\title{
Anesteziyoloji ve reanimasyon yoğun bakım ünitesinde yatan hastalarda gelişen kateter ilişkili üriner sistem infeksiyonlarının irdelenmesi
}

\section{Investigation of catheter-related urinary tract infections in intensive care unit patients of anesthesiology and reanimation}

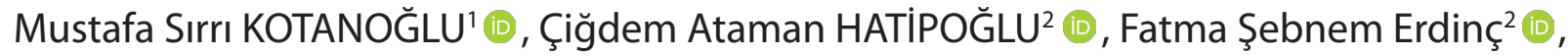

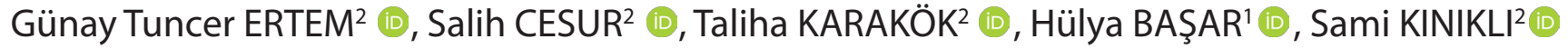

'Ankara Eğitim ve Araştırma Hastanesi, Anesteziyoloji ve Reanimasyon Kliniği
${ }^{2}$ Ankara Eğitim ve Araştırma Hastanesi, Infeksiyon Hastalıkları ve Klinik Mikrobiyoloji Kliniği

\section{ÖZ}

Amaç: Bu çalışmanın amacı, Ankara Eğitim ve Araştırma Hastanesi, Anesteziyoloji ve Reanimasyon yoğun bakım ünitesinde yatan hastalarda gelişen kateter ilişkili üriner sistem infeksiyonlarının hızlarının ve infeksiyon etkenlerinin retrospektif değerlendirilmesidir.

Gereç ve Yöntemler: Çalışmaya, 1 Ocak 2018-31 Aralık 2019 tarihleri arasında Anesteziyoloji ve Reanimasyon yoğun bakım ünitesi (ARYBÜ)'nde yatan ve kateter ilişkili üriner sistem infeksiyonu tanısı konulan hastalar dahil edildi. Hasta verileri enfeksiyon kontrol hemşirelerinin günlük vizitleri ve enfeksiyon hastalıklarının günlük konsültasyon kayıtlarından ve Ulusal Hastane Enfeksiyonları Sürveyans Ağı INFLINE programı verilerinden, laboratuvar verileri ise Mikrobiyoloji laboratuarından elde edildi. Hastaların demografik verileri, üriner kateterle ilişkili enfeksiyonları, enfeksiyon etkenleri, hastalardaki komorbid durumların varlığı kaydedildi.

Bulgular: Anesteziyoloji ve Reanimasyon yoğun bakım ünitesinde iki yıllık sürede 17910 hasta gününde 1243 hasta takip edilmişti. Hastaların üriner kateter günü 17470 gün idi. Çalışmanın yapıldığı dönemde toplam 85 hastaya 116 Ki-ÜSi tanısı konuldu. Üriner kateter kullanım oranı 0.97, kateterle ilişkili üriner sistem infeksiyonu hızı (Ki-ÜSi) ise 6.63 olarak saptandı. 2019 yılı Sağlık Bakanlığı Eğitim ve Araştırma Hastaneleri ARYBÜ'lerinin sürveyans verileri ile karşılaştırıldığında; hastanemizin ARYBÜ üriner kateter kullanım oranının \%25 persentil ile uyumlu olduğu, KI-ÜSE hızının ise \%90 persentilin üzerinde olduğu saptandı.Hastaların 47 (\% 55)'si kadın, 38 (\%45)'i erkek, yaş median değeri 66 idi. Hastaların tümünde üriner kateter mevcuttu. Hastalarda görülen komorbid hastalıklar; 44 (\%51.8) hastada nörolojik hastalık (serebrovasküler olay, demans vb.), 40 (\%47.1) hastada hipertansiyon, 28 (\%32.9) hastada diyabetes mellitus, 20 (\%23.5) hastada KOAH ve iki (\%2.4) hastada kronik böbrek hastalığı olarak belirlendi. Hastaların 72 (\%84.7)'si entübe idi ve 19 (\%22.4)'unda dekübit ülseri mevcuttu. Kí-ÜSi etkenlerinin dağılımı incelendiğinde 27 (\%31.8) hastada birden fazla etkenin izole edildiği görüldü. Üriner sistem etkenleri 18 (\%21.2) hastada Klebsiella türleri (spp.), 10 (\%11.8) hastada Escherichia coli, dokuz (\%10.6) hastada Enterococcus spp.,sekiz (\%9.4) hastada Pseudomonas spp., yedi (\%8.2) hastada Proteus spp., dört (\%4.7) hastada Acinetobacter spp., bir (\%1.2) hastada Staphylococcus aureus ve bir (\%1.2) hastada Enterobacter spp. olarak belirlendi. KiÜsi saptanan 85 hastanın 19'unda kan kültüründe de aynı etken izole edildi. Kan kültüründen en sık izole edilen etkenler sırasıyla; altı olguda birden fazla etken, yedi Klebsiella spp., iki E. coli ve iki Enterococcus spp., bir Acinetobacter spp., bir Proteus spp. olarak belirlendi.

Sonuç: Yoğun bakım ünitelerinde kateter ilişkili üriner sistem infeksiyonu oranlarının azaltılması için üriner kateter takılması endikasyonlarının iyi belirlenmesi, gereklilik ortadan kalktığında kateterin çekilmesi ve enfeksiyon kontrol önlemlerine dikkat edilmesi uygun bir yaklaşım olacaktır. Yoğun bakım ünitesinde yatan hastalarda hastane infeksiyonu etkenlerinin belirlenmesi, ampirik tedavide yol gösterici olacağından mortalite ve morbidite oranlarının azaltılmasına da katkı sağlayacaktır.

Anahtar kelimeler: yoğun bakım ünitesi; kateter ilişkili üriner sistem infeksiyonu; risk faktörleri

Sorumlu Yazar*: Salih CESUR, Ankara Eğitim ve Araştırma Hastanesi, İnfeksiyon Hastalıkları ve Klinik Mikrobiyoloji Kliniği

E-posta: scesur89@yahoo.com,

ORCID: 0000-0003-4960-7375

Gönderim: 22/09/2020 Kabul: 23/11/2020

Doi: $10.18663 /$ tjcl.798614 


\section{ABSTRACT}

Aim: The aim of this study is to retrospectively evaluate the rates and infectious factors of healthcare-associated urinary tract infections in patients with Ankara Training and Research Hospital, Anesthesia and Reanimation intensive care unit.

Material and Methods: Patients hospitalized in the Anesthesia and Reanimation intensive care unit (ICU) between January 1, 2018 and December 31, 2019 and diagnosed with healthcare-related urinary tract infection were included in the study. Patient data were obtained from the daily visits of infection control nurses and daily consultation records of infectious diseases, while laboratory data were obtained from the Microbiology laboratory. The rate of infection associated with urinary catheter, distribution of infectious agents, and presence of comorbid conditions in patients were recorded.

Results: Totaly 1243 patients were followed up for 17,910 patient days in the Anesthesia and Reanimation intensive care unit for two years. The urinary catheter day of the patients was 17470 days. A total of 85 patients were diagnosed with 116 urinary catheter-related urinary tract infections. Forty- seven of the patients (55\%) were female, $38(45 \%)$ were male, age median value was 66.During the period of the study, it was found that the rate of urinary catheter use was 0.97 , and the rate of catheterrelated urinary tract infection (CI-UTI) was 6.63. When the rate of urinary catheter use in the Anesthesia and Reanimation intensive care unit in our hospital is compared with the 2019 Ministry of Health Education and Research Hospitals Anesthesia ICU surveillance data; it was found that the rate of urinary catheter use was consistent with the 25th percentile (0.97), and the rate of $\mathrm{Cl}$-UTI was above the 90th percentile (3.8).The most common comorbid diseases in patients were at least one neurological disease (cerebrovascular event, dementia, etc.) in 44 (51.8\%) patients, hypertension in 40 (47.1\%), diabetes mellitus in $28(32.9 \%)$, chronic obstructive pulmonary diseases in $20(23.5 \%)$ patients and $2.4 \%$ of the patients were identified as chronic kidney disease. All patients had urinary catheters. $72(84.7 \%)$ of the patients were intubated and $19(22.4 \%)$ had decubitus ulcers.Distribution of agents causing urinary tract infection; multiple agents in 27 (31.8) patients, Klebsiella species (spp.) in 18 (21.2\%) patients, E.coli in 10 (11.8\%) patients, Enterococcus spp. in nine (10.6\%) patients, Pseudomonas spp in eight (9.4\%) patients, Proteus spp. in seven (8.2\%) patients, Acinetobacter spp. in four (4.7\%) patients, Staphylococcus aureus in one (1.2\%) patient, Enterobacter spp. in one (1.2\%) patient were determined.In 19 of 85 patients with urinary system infection, the agent was also isolated from the blood culture. The most common factors isolated from blood culture are; 36.8\% Klebsiella spp., 31.6\% multiple agents, 10.5\% E.coli and 10.5\% Enterococcus spp. was determined.

Conclusion: As a result, it would be an appropriate approach to determine the indications for urinary catheter insertion well and withdraw the catheter when the necessity is eliminated in order to reduce the urinary system infection rates associated with healthcare in the ICU. Determining the factors of nosocomial infection in patients hospitalized in the intensive care unit will contribute to the reduction of mortality and morbidity rates as it will be a guide in empirical treatment.

Keywords: intensive care unit; catheter-related urinary tract infection; risk factors

\section{Giriş}

Yoğun bakım üniteleri (YBÜ), hastanelerde sağlıkbakımıyla ilişkili infeksiyonların en sık görüldüğü üniteler olup, bu ünitelerde görülen infeksiyonlar önemli bir mortalite ve morbidite nedenidir.[1] Yoğun bakım ünitesinde infeksiyon oranları, invazif aletlerin kullanııması, yatış süresinin uzaması, altta yatan hastalıkların çeşitliliği ve yoğun bakımın özelliklerinden dolayı yüksektir.[2] YBÜ'ler hastanedeki tüm yatakların en fazla \%10'unu oluşturmasına karşın YBÜ'lerde gelişen enfeksiyonlar, tüm hastane enfeksiyonlarının yaklaşık \%20-25'ini oluşturmaktadır.[3] Hastanelere ve bölümlere göre değişmekle birlikte en sık görülen sağlık bakımı ile ilişkili infeksiyonlar üriner sistem infeksiyonları (ÜSi) olup, tüm sağlık bakımı ile ilişkili infeksiyonların \%36'sını oluşturur. Kateterle ilişkili üriner sistem enfeksiyonu (KI-ÜSE) üriner sistem infeksiyonlarının \%80'ini oluşturur.[4] Bu çalışmada, Ankara Eğitim ve Araştırma Hastanesi, Anesteziyoloji ve Reanimasyon yoğun bakım ünitesinde (ARYBÜ) yatan hastalarda gelişen kateter ile ilişkili üriner sistem infeksiyonlarının hızlarının ve infeksiyon etkenlerinin, retrospektif olarak değerlendirilmesi amaçlandı.

\section{Gereç ve Yöntemler}

Çalışmada, 1 Ocak 2018-31 Aralık 2019 tarihleri arasında ARYBÜ'de yatan ve KI-ÜSE tanısı konulan hastalar dahil edildi. Hasta verileri enfeksiyon kontrol hemşirelerinin günlük vizitleri, enfeksiyon hastalıklarının günlük konsültasyon kayıtları ve Ulusal Hastane Enfeksiyonları Sürveyans Ağı INFLiNE programı verilerinden, laboratuvar verileri ise Mikrobiyoloji laboratuarından elde edildi. Hastaların demografik verileri, kateterle ilişkili üriner infeksiyonları, infeksiyon etkenleri ve komorbid durumların varlığı kaydedildi. Üriner kateter kullanım oranı ve Ki-ÜSE hızı aşağıdaki formüller ile hesaplandı. 
Üriner kateter kullanım oranı= Üriner kateter günü / Hasta günü Kateterle ilişkili üriner sistem infeksiyonu hızı = Kateterle ilişkili üriner sistem infeksiyonu sayısı/ üriner kateter günüX1000

Çalışmanın verileri Excel programına girildi ve istatistiksel analizler SPSS programı ile yapıldı. Çalışma için Ankara Eğitim ve Araştırma Hastanesi Klinik Araştırmalar Etik Kurul'undan 20/08/2020 tarihinde E-20 sayı numaralı onay alındı. Hastalara aydınlatılmış onam belgesi imzalatıldı.

\section{Bulgular}

ARYBÜ'de iki yıllık sürede 17910 hasta gününde 1243 hasta takip edilmişti. Hastaların üriner kateter günü 17470 gün idi.
Çalışmanın yapıldığı dönemde toplam 85 hastaya 116 Kİ-ÜSE tanısı konuldu. Üriner kateter kullanım oranı 0.97, kateterle ilişkili üriner sistem infeksiyonu hızı (KI-ÜSE) ise 6.63 olarak saptandı. 2019 yılı Sağlık Bakanlığı Eğitim ve Araştırma Hastaneleri ARYBÜ'lerinin sürveyans verileri ile karşılaştırıldığında; ARYBÜ üriner kateter kullanım oranının \%25 persentil ile uyumlu olduğu, Ki-ÜSE hızının ise \%90 persentilin üzerinde olduğu saptandı.

Çalışma süresince ARYBÜ'de yatan hasta sayısı, hasta günü, üriner kateter günü, ÜSİ sayısı, üriner kateter kullanım oranı ve Ki-Üsi oranı Tablo 1'de verildi.

\section{Tablo 1: Hastaların üriner kateter günü, ÜSİ sayısı, üriner kateter kullanım oranı ve KI-ÜSi oranı \\ ARYBÜ Hasta sayısı Hasta günü Üriner kateter günü Üriner sistem enfeksiyonu Üriner kateter kullanım oranı KI-ÜSE \begin{tabular}{|l|l|l|l|l|l}
1243 & 17910 & 17470 & 116 & 0.97 & 6.63 \\
\hline
\end{tabular}}

Toplam 85 hastanın 47'si kadın (\%55.3), 38'i (\%44.7) erkek hasta idi. Hastaların median yaşı 66 olarak belirlendi. Hastaların tümünün üriner kateteri vardı. Hastaların ilk KI-ÜSi atakları baz alınarak risk faktörleri ve etkenler belirlendi.

Hastaların 44 (\%52)'ünde nörolojik hastalık, 40 (\%47)'ında hipertansiyon, 28 (\%33)'inde diyabetes mellitus, 20 (\%23.5)'sinde $\mathrm{KOAH}$, iki (\%2.4)'sinde kronik böbrek hastalığı mevcuttu. Hastaların 72 (\%84.7)'si entübe idi, 19 (\%22.4)'unda dekübit ülseri mevcuttu.

Üriner sistem infeksiyonu etkenlerinin dağılımı incelendiğinde; 27 (31.8) hastada birden fazla etken olduğu görüldü. 18 (\%21.2) hastada Klebsiella spp., 10 (\%11.8) hastada E. coli, dokuz (\%10.6) hastada Enterococcus spp., sekiz (\%9.4) hastada Pseudomonas spp., yedi (\%8.2) hastada Proteus spp., dört (\%4.7) hastada Acinetobacter spp., bir (\%1.2) hastada Staphylococcus aureus,bir (\%1.2) hastada Enterobacter spp. etken olarak izole edildi. İdrar kültüründen izole edilen etkenlerin dağılımları Şekil 1'de gösterildi.

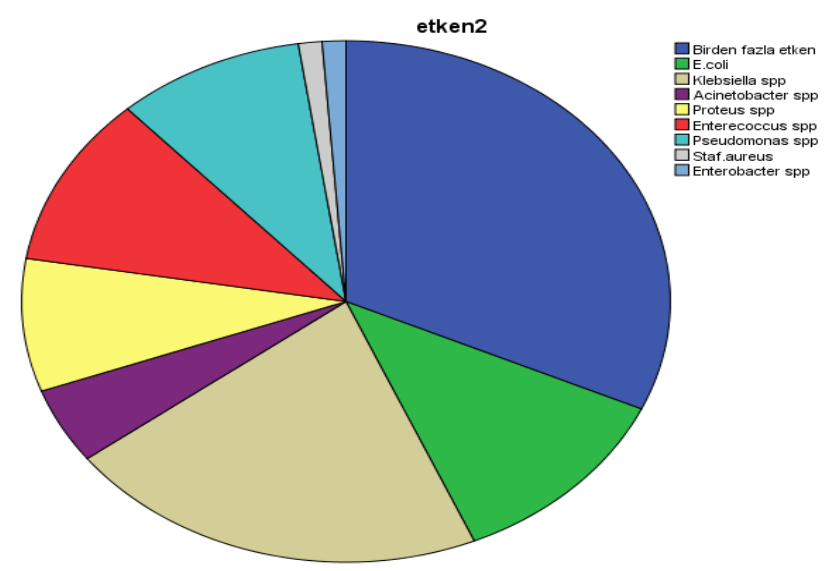

Şekil 1. Üriner sistem infeksiyonu olan hastalarda kültürden izole edilen etkenlerin dağılımları
Üriner sistem infeksiyonu olan 85 hastanın 19 (\%22.4)'unda kan kültüründen de aynı etken izole edildi. Kan kültüründen en sık izole edilen etkenler sırasıyla; \%36.8 Klebsiella spp., \% 31.6 birden fazla etken, \%10.5 E.coli ve \%10.5 Enterococcus spp. olarak belirlendi. Üriner sistem infeksiyonuna sekonder bakteriyemi gelişen 19 hastanın 13'ü (\%47) kadın, altı'sı (\%38) ise erkekti.

Kan kültüründen izole edilen etkenlerin dağılımı Tablo 2'de gösterildi.

\begin{tabular}{|c|c|c|}
\hline Etkenler & Sayı & (\%) \\
\hline $\begin{array}{l}\text { Birden fazla etken (E.coli, Klebsiella spp., Acineto- } \\
\text { bacter spp., Pseudomonas spp., Proteus spp. vb.) }\end{array}$ & 6 & 31.6 \\
\hline Klebsiella spp. & 7 & 36.8 \\
\hline E.coli & 2 & 10.5 \\
\hline Enterococcus spp. & 2 & 10.5 \\
\hline Acinetobacter spp. & 1 & 5.3 \\
\hline Proteus spp. & 1 & 5.3 \\
\hline Toplam & 19 & 100 \\
\hline
\end{tabular}

\section{Tartışma}

YBÜ'de görülen sağlık bakımıyla ilişkili infeksiyon türleri (kateter ilişkili üriner sistem, ventilatör ilişkili pnömoni, kateter ilişkili kan dolaşımı vb.) ve oranlarının hastaneler ve YBÜ'ler arasında farklılıklar gösterdiği bildirilmektedir. Pnömoniler, üriner sistem infeksiyonları ve kan dolaşımı infeksiyonları nozokomiyal infeksiyonların yaklaşık \%68-77'sini oluşturmaktadır.[1,6,7]

KI-ÜSE, artan morbidite ve mortalite ile ilişkilidir ve sekonder kan dolaşımı infeksiyonlarının en yaygın nedenidir. KI-ÜSE gelişimi için risk faktörleri arasında uzun süreli kateterizasyon, kadın cinsiyet, ileri yaş ve diyabet yer almaktadır.[8] 
Kalıcı idrar sondası yerleştirilmesinin kanıta dayalı olmadığı veya uygunsuz olduğu, bu durumun hasta bakım yükünü ve maliyeti önemli oranda artırdığı, hastada rahatsızlığa ve aktivitelerinde kısıtlamalara neden olduğu bildirilmektedir. En iyi uygulama kılavuzları, personelin aktif katılımını eğitim ve izleme ile birleştiren çok yönlü müdahalelerin, tek bir müdahaleye odaklananlara göre uygulama değişikliği sağlamada daha etkili olduğunu göstermiştir. Ki-Üsi, üriner sistem infeksiyonlarının çoğunu temsil eder, tüm hastanede yatan hastalarda ÜSi'lerin yaklaşık \%67'sini, YBÜ'lerde yatan hastalarda ise \%97'sini oluşturur. Hastanede yatan hastaların \%12 ila \%16'sına kısa süreli kalıcı üriner kateter takılmaktadır ve bu kateterlerin çoğunun uygunsuz takıldığı tespit edilmiştir (5). KI-ÜSi riski, kateterizasyon süresi ile önemli ölçüde artar. Bu durum, önemli oranda bakım yüküne, hastane maliyetlerinde artışa, hastada rahatsızlığa, ağrı ve aktivite kısıtlamaları gibi istenmeyen durumlara neden olur. Yapılan bir çalışmada, 48 saatten uzun süre hastanede yatarak tedavi gören hastaların \%1.7'sinin ÜSi geçirdiği ve hastanede kalış sürelerinin uzamasına (ortalama 4 gün) neden olduğu bildirilmiştir.[5,9]

Bir meta-analiz çalışmasında, KI-ÜSE için risk faktörlerinin kadın cinsiyet, kateterizasyon süresinin uzun olması, hastalarda diabetes mellitus varlığı, daha önce kateterizasyon uygulanması, hastanede ve YBÜ'de daha uzun süre yatış olduğu bildirilmiştir. Ek olarak, Kì-Üsílerin mortalitede artışa neden olduğu rapor edilmiştir.[10]

Çalışmamızda da Ki-Üsi hastaları arasında kadın cinsiyet daha fazla idi. Hastaların \%33'ünde diyabetes mellitus mevcuttu. Diğer en sık görülen komorbid hastalıklar ise hipertansiyon, nörolojik hastalık ve KOAH idi.

Yoğun bakım ünitelerinde sağlık bakımıyla ilişkili infeksiyon etkeni mikroorganizmalar da hastaneler ve YBÜ'leri arasında farklılıklar gösterir. Deniz ve ark. [6] Anestezi yoğun bakım ünitesinde üriner sistem infeksiyonlarından en sık izole edilen etkenleri sırasıyla; Pseudomonas aureginosa, Acinetobacter baumannii ve Escherichia coli olarak bildirmişlerdir.

Sunduğumuz çalışmada, üriner sistem infeksiyonu etkenlerinin dağılımı sıklık sırasına göre; 27 hastada birden fazla etken, 18 hastada Klebsiella türleri (spp.), 10 hastada E.coli, dokuz hastada Enterococcus spp.,sekiz hastada Pseudomonas spp., yedi hastada Proteus spp., dört hastada Acinetobacter spp., bir hastada Staphylococcus aureus, bir hastada Enterobacter spp. olarak belirlendi.

Öncül ve ark. [11] yoğun bakım ünitesinde gelişen infeksiyonların 42'sini $(\% 28,4)$ primer bakteremi veya santral venöz kateter ilişkili kan dolaşımı infeksiyonu (SVK-KDi), 40'ını
(\%27) ventilatör ilişkili pnömoni (ViP) veya trakeobronşit, 22'sini $(\% 14,9)$ pnömoni veya pnömoni dışı alt solunum yolu infeksiyonu, 38'ini $(\% 25,7)$ üriner sistem infeksiyonu (ÜSi), altı'sını $(\% 4,1)$ yumuşak doku enfeksiyonu olarak bildirmişlerdir. Üriner sistem enfeksiyonlarında etkenlerin dağılımını \%31,6 Pseudomonas spp., \%31,6 Candida spp., $\% 14,6$ E. coli olarak bildirmişlerdir. Komorbid hastalıklar açısından tüm infeksiyon gelişen hastalarda en sık görülen altta yatan hastalığın \%57,7 oranıyla serebrovasküler hastalık (SVH) olduğu, diyabetin yumuşak doku enfeksiyonu olan hastalarda daha fazla görüldüğü rapor etmişlerdir.

Dizbay ve ark. [12] Anestezi Reanimasyon ve Nöroloji yoğun bakım ünitesinde yaptıkları çalışmada üriner istem infeksiyonlarında en sık izole edilen mikroorganizmaları Pseudomonas, Acinetobacter ve E.coli olarak bildirmişlerdir.

Yapılan çok merkezli bir çalışmada YBÜ'lerde en sık görülen hastane kaynaklı infeksiyonlar; pnömoniler (\%40), üriner sistem infeksiyonları $(\% 20,5)$ ve yara yeri infeksiyonu (\%13) olarak bildirilmiştir.[5,6] Deniz ve ark. [6] yeniden yapılandırılan Anestezi reanimasyon ünitesinde yapılandırma öncesi ve yapılandırma sonrası pnömoni oranlarını \%32,7-14,6; üriner sistem infeksiyonu oranlarını \%18,7-10,4; kateter infeksiyonu oranlarını \%12-11; ve yara yeri infeksiyonunu oranlarını \%4,7-4,7 olarak bildirmişlerdir.

Kateterle ilişkili bakteriürisi olan yatan her 27 hastanın birinde sekonder bakteriyemi geliştiği rapor edilmiştir.[13] Sistematik bir değerlendirmede, hastanede yatan üriner kateterle ilişkili bakteriürisi olan erkek hastalarda bakteriyemi gelişme riskinin kadın hastalardan daha yüksek olduğu bildirilmiştir. Bu nedenle, yüksek riskli hastalarda zorunlu olmadıkça üriner kateter takılmasından kaçınılması önerilmektedir.[14]

Sunduğumuz çalışmada üriner sistem infeksiyonu olan 85 hastanın 19'unda kan kültüründen de etken izole edildi, bakteriyemi mevcuttu. Kan kültüründen en sık izole edilen etkenler sırasıyla ; \%36.8 Klebsiella spp., \% 31.6 birden fazla etken, \%10.5 E.coli ve \%10.5 Enterococcus spp. olarak belirlendi. Üriner sistem infeksiyonuna sekonder bakteriyemi gelişen 19 hastanın 13'ü (\%47) kadın, altı'sı (\%38) ise erkekti. Sunduğumuz çalışmada literatürden farklı olarak kadınlarda Ki-Üsi'ye sekonder bakteriyemi oranı erkeklerden daha fazla saptandı.

Çalışmamızda ARYBÜ'de üriner kateter kullanım oranı 0.97, KIÜSi hızı ise 6.63 olarak belirlendi. Bu oran ülkemizdeki diğer eğitim ve araştırma hastanelerinin 2019 sürveyans verileri ile karşılaştırıldığında; ARYBÜ'deki üriner kateter kullanım oranının 25. persentil ile uyumlu olduğu, Ki-ÜSE hızının ise 90. persentilin üzerinde olduğu saptandı.[15] 


\section{Sonuç}

YBÜ'de sağlık bakımıyla ilişkili üriner sistem infeksiyon oranlarının azaltılması için üriner kateter takılması endikasyonlarının iyi belirlenmesi, gereklilik ortadan kalktığında kateterin çekilmesi ve enfeksiyon kontrol önlemlerine dikkat edilmesi uygun bir yaklaşım olacaktır. Yoğun bakım ünitesinde yatan hastalarda hastane infeksiyonu etkenlerinin belirlenmesinin, ampirik tedavide yol gösterici olacağı ve mortalite ve morbidite oranlarının azaltılmasına da katkı sağlayacağı görüşündeyiz.

\section{Çıkar çatışması/finansal destek beyanı}

Bu yazıdaki hiçbir yazarın herhangi bir çıkar çatışması yoktur. Yazının herhangi bir finansal desteği yoktur.

\section{Kaynaklar}

1. Richards MJ, Edwards JR, Culver DH, Gaynes RP. Nosocomial infections in combined medical-surgical intensive care units in the United States. Infect Control Hosp Epidemiol 2000; 21: 510-5.

2. Eggimann P, Pittet D. Infection control in the ICU. Chest 2001; 120: 2059-93.

3. Erbay $H$, Yalcın AN, Serin $S$ et al. Nosocomial infections in intensive care unit in a Turkish university hospital: a 2-year survey. Intensive Care Med 2003; 29: 1482-8.

4. Biberoğlu K. Yoğun bakım ünitesi enfeksiyonları: tanımlar, epidemiyoloji ve risk faktörleri. Yoğun Bakım Dergisi 2003; 3:73-80.

5. Parker V, Giles M, Graham L, Suthers B, Watts W, O'Brien T, and Searles A. Avoiding inappropriate urinary catheter use and catheter-associated urinary tract infection (CAUTI): a pre-post control intervention study. BMC Health Serv Res. 2017; 17: 314.

6. Deniz A, Erhan OL, Bayar MK, Karatepe U, Demirel İ. Yeniden Yapılandırılan Anestezi Yoğun Bakım Ünitesinde Enfeksiyon Oranlarındaki Değişimlerin İncelenmesi: Retrospektif Calışma. Turk J Anaesthesiol Reanim 2017; 45: 353-60.

7. Ponce de Leon-Rosales SP, Molinar-Ramos F, DominguezCherit G, Rangel-Frausto MS, Vazquez-Ramos VG. Prevalence of infections in intensive care units in Mexico: a multicenter study. Crit Care Med 2000; 28: 1316-21.
8. Flores-Mireles AN, Walker JN, Caparon M, and Hultgren SJ. Urinary tract infections: epidemiology, mechanisms of infection and treatment options Nat Rev Microbiol 2015; 13: 269-84.

9. Mitchell BG, Ferguson JK, Anderson M, Sear J, Barnett A. Length of stay and mortality associated with healthcare-associated urinary tract infections: a multi-state model. J Hosp Infect 2016; 93: 92-99.

10. Fei Li , Meixuan Song , Linxia Xu , Bo Deng, Shiqin Zhu, Xianrong Li. Risk factors for catheter-associated urinary tract infection among hospitalized patients: A systematic review and metaanalysis of observational studies.J Adv Nurs 2019; 75: 517-23.

11. Öncül A, Koçulu S, Elevli K. Bir devlet hastanesinin yoğun bakım ünitelerinde kazanılan hastane enfeksiyonlarının epidemiyolojisi. Şişli Etfal Hastanesi Tıp Bülteni 2012; 46: 60-66.

12. Dizbay A, Altunçekiç A, Kanat DÖ, Sezer BE, Baş S, Özer F, Arman D. Anestezi-Reanimasyon ve Nöroloji Yoğun Bakım Ünitelerinde Gelişen Nozokomiyal infeksiyonlar: İki yılın değerlendirmesi. Hastane İnfeksiyonları Dergisi 2007; 4: 252-7.

13. Saint S, Kaufman SR, Rogers MA, Baker PD, Boyko EJ, Lipsky BA. Risk factors for nosocomial urinary tract-related bacteremia: $A$ case-control study. American Journal of Infection Control 2006; 34: 401-7.

14. Conway LJ, Carter EJ, Larson EL. Risk Factors for Nosocomial Bacteremia Secondary to Urinary Catheter-Associated Bacteriuria: A Systematic Review. Urol Nurs 2015 ; 35: 191-203.

15. Ulusal Sağlık Hizmeti İlişkili Enfeksiyonlar Sürveyans Ağı Özet Raporu 2019. T.C. Sağlık Bakanlığı Halk Sağlığı Genel Müdürlüğü Bulaşııı Hastalıklar Dairesi Başkanlığı. https://hsgm.saglik.gov.tr/ depo/birimler/Bulasici-hastaliklar-db/hastaliklar/SHIE/Raporlar/ USHESA_Ozet_Raporu_2019.pdf 